PAPER

\title{
Limitations of sniff nasal pressure in patients with severe neuromuscular weakness
}

\author{
N Hart, M I Polkey, T Sharshar, L Falaize, B Fauroux, J C Raphaël, F Lofaso
}

J Neurol Neurosurg Psychiatry 2003;74:1685-1687

See end of article for authors' affiliations ......................

Correspondence to: Professor F Lofaso, Service de PhysiologieExplorations

Fonctionnelles, Raymond Poincaré Hôpital, Garches 92380, France; f.lofaso@ rpc.ap-hop-paris.fr

Received 22 August 2002 In revised form

21 January 2003

Accepted 14 March 2003
Background: Inspiratory muscle strength in patients with neuromuscular disorders can be assessed using sniff inspiratory nasal pressure $\left(\mathrm{Pn}_{\mathrm{sn}}\right)$ and maximum inspiratory mouth pressure $\left(\mathrm{PI}_{\text {max }}\right)$. However, the relative merits of $\mathrm{Pn}_{\mathrm{sn}}$ against $\mathrm{PI}_{\max }$ are not known in patients with severe neuromuscular disease.

Objective: To investigate whether severity of disease modifies the relation between $\mathrm{Pn}_{\mathrm{sn}}$ and $\mathrm{PI}_{\max }$.

Methods: Vital capacity $(\mathrm{VC}), \mathrm{Pn}_{\mathrm{sn}}$, and $\mathrm{PI}_{\max }$ were measured in 258 patients with neuromuscular disorders.

Results: Data were analysed from 241 patients, 17 being unable to perform $\mathrm{PI}_{\max }$ or $\mathrm{Pn}_{\text {sn }}$ manoeuvres. The correlation between $\mathrm{Pn}_{\text {sn }}$ and $\mathrm{PI}_{\max }$ was $+0.94(\mathrm{p}<0.0001)$, with a mean (SD) difference between $\mathrm{Pn}_{\text {sn }}$ and $\mathrm{PI}_{\text {max }}$ of $-4.8(21.2) \mathrm{cm} \mathrm{H} \mathrm{O}$ (the limits of agreement were 37.6 and $-47.2 \mathrm{~cm} \mathrm{H}$ O). $\mathrm{VC}$ (\% predicted) was positively correlated with $\mathrm{Pn}_{\mathrm{sn}} / \mathrm{PI}_{\max }(r=+0.86 ; \mathrm{p}<0.0001)$, with a lower $\mathrm{Pn}_{\mathrm{sn}} / \mathrm{PI}_{\max }$ value in patients with a VC $<40 \%$ of predicted than in those with a VC $>40 \%(0.80(0.35)$ v $1.04(0.41)$; $\mathrm{p}<0.0001$ ).

Conclusions: $\mathrm{PI}_{\max }$ is greater than $\mathrm{Pn}_{\mathrm{sn}}$ in patients with a severe restrictive ventilatory defect caused by neuromuscular disease. $\mathrm{Pn}_{\mathrm{sn}}$ may not accurately reflect inspiratory muscle strength in such patients and it is thus advisable to use both tests.
A lthough sniff inspiratory nasal pressure $\left(\mathrm{Pn}_{\mathrm{sn}}\right)$ and maximum inspiratory mouth pressure $\left(\mathrm{PI}_{\max }\right)$ are used to assess inspiratory muscle strength in patients with neuromuscular disorders, ${ }^{12}$ it is unclear whether the values for $\mathrm{Pn}_{\mathrm{sn}}$ are higher than $\mathrm{PI}_{\max }$. Stefanutti et al reported that the airway pressure during a sniff manoeuvre was higher than the pressure generated during a maximal static inspiratory manoeuvre, ${ }^{1}$ whereas a recent study by Iandelli et al suggested the opposite, especially in patients with severe neuromuscular disorders. ${ }^{2}$ However, in those studies less than $20 \%$ of the patients had a vital capacity (VC) below $40 \%$ of predicted, which is a level that can be considered to indicate a severe restrictive ventilatory defect (all patients with symptoms of nocturnal hypoventilation and a VC less than $50 \%$ of predicted should be considered for long term non-invasive ventilation ${ }^{3}$ ). Thus our aim in the current study was to examine the affect of moderate to severe lung restriction on the relation between $\mathrm{Pn}_{\mathrm{sn}}$ and $\mathrm{PI}_{\max }$ in patients with neuromuscular disease.

\section{METHODS}

We studied 258 patients with neuromuscular disorders as part of routine clinical evaluation over a three year period at the Raymond Poincaré hospital. Seventeen patients were excluded: nine were unable to perform $\mathrm{PI}_{\max }$ manoeuvres and eight were unable to perform $\mathrm{Pn}_{\mathrm{sn}}$ manoeuvres.

All the tests were conducted in a single session, with patients in a seated position. $\mathrm{Pn}_{\mathrm{sn}}$ and $\mathrm{PI}_{\max }$ were both measured from functional residual capacity (FRC) in a standard manner, according to previously described methods $\left(\mathrm{PI}_{\max }\right.$ is an isometric manoeuvre, while $\mathrm{Pn}_{\mathrm{sn}}$ is a quasiisometric manoeuvre). ${ }^{45} \mathrm{Pn}_{\mathrm{sn}}$ was measured during 10 maximal sniffs, ${ }^{6}$ while $\mathrm{PI}_{\max }$ was measured with a flanged mouthpiece with the manoeuvres repeated at least three times or until two identical readings were obtained. ${ }^{7}$ All signals were measured using a differential pressure transducer (Validyne, Northridge, CA, USA), amplified by a carrier amplifier (Validyne), and passed through an analogue-digital board to a computer running Acqknowledge software (Biopac System, Goleta, CA, USA). Patients received strong verbal encouragement with visual feedback, as previous studies have suggested. ${ }^{8}$ Spirometry and lung volumes were measured according to standard guidelines and reported as per cent predicted. ${ }^{9}$ Severity of disease was defined according to VC ( $\%$ predicted), with a VC $<40 \%$ being arbitrarily defined as severe restrictive lung disease. $\mathrm{PI}_{\max }$ and $\mathrm{Pn}_{\mathrm{sn}}$ are expressed as positive values although they are negative pressures with respect to atmosphere.

\section{STATISTICAL ANALYSIS}

All results are expressed as mean (SD). The correlation between $\mathrm{Pn}_{\mathrm{sn}}$ and $\mathrm{PI}_{\max }$ was assessed using linear regression analysis. Agreement between $\mathrm{Pn}_{\mathrm{sn}}$ and $\mathrm{PI}_{\max }$ was determined using a Bland and Altman plot. ${ }^{10} \mathrm{Pn}_{\mathrm{sn}} / \mathrm{PI}_{\max }$ was used to evaluate the relations between $\mathrm{Pn}_{\mathrm{sn}}, \mathrm{PI}_{\max }$, and VC using linear regression analysis. The difference between $\mathrm{Pn}_{\mathrm{sn}} / \mathrm{PI}_{\max }$ in the patients with a VC $<40 \%$ of predicted and patients with a VC $>40 \%$ of predicted was assessed using an unpaired $t$ test.

\section{RESULTS}

Two hundred and forty one patients with neuromuscular disorders were eligible for analysis (table 1). Their mean (SD) age was 45.1 (16.4) years and 58\% were male. No problems were encountered with air leaks during the $\mathrm{PI}_{\max }$ manoeuvre using the flange mouthpiece. Mean VC (\% predicted) was $51.9(26.0) \%$, mean $\mathrm{PI}_{\max }$ was $45.6(28.2) \mathrm{cm} \mathrm{H}_{2} \mathrm{O}$, and mean $\mathrm{Pn}_{\mathrm{sn}}$ was 41.5 (26.4) $\mathrm{cm} \mathrm{H} \mathrm{H}_{2} \mathrm{O}(35.2 \%$ of patients had a VC $<40 \%$ of predicted and $37.8 \%$ were receiving non-invasive ventilation).

Abbreviations: FRC, functional residual capacity; NIV, non-invasive ventilation; PImax, inspiratory mouth pressure; Pnsn, sniff inspiratory nasal pressure; VC, vital capacity 
Table 1 Patients with neuromuscular disorders eligible for analysis

\begin{tabular}{llr}
\hline & Diagnosis & N \\
\hline Muscle & Myotonic dystrophy & 64 \\
& Duchenne muscular dystrophy & 23 \\
& Congenital myopathies & 19 \\
& Acid maltase deficiency & 16 \\
& Limb girdle muscular dystrophy & 14 \\
& Mitochondrial myopathy & 3 \\
& Becker's muscular dystrophy & 3 \\
& Facioscapulohumeral dystrophy & 3 \\
& Congenital muscular dystrophy & 3 \\
& Inclusion body myositis & 1 \\
& Polymyositis & 1 \\
Nerve & Poliomyelitis & 41 \\
& Guillain-Barré syndrome & 8 \\
& Spinal muscular atrophy & 7 \\
& Charcot-Marie-Tooth & 2 \\
Junction & Bilateral diaphragm paralysis & 1 \\
& Myasthenia gravis & \\
\hline
\end{tabular}

As expected, there was a positive correlation between $\mathrm{Pn}_{\mathrm{sn}}$ and $\mathrm{PI}_{\max }(r=+0.94, \mathrm{p}<0.0001)$. However, the agreement between $\mathrm{Pn}_{\mathrm{sn}}$ and $\mathrm{PI}_{\max }$, assessed using a Bland and Altman plot $^{10}$ was relatively poor. Figure 1 shows a Bland and Altman plot with a mean difference between $\mathrm{Pn}_{\mathrm{sn}}$ and $\mathrm{PI}_{\max }$ of -4.8 (21.2) $\mathrm{cm} \mathrm{H}_{2} \mathrm{O}$ and limits of agreement of 37.6 and $-47.2 \mathrm{~cm}$ $\mathrm{H}_{2} \mathrm{O}$. Despite this, we observed a positive correlation between VC $\left(\%\right.$ predicted) and $\mathrm{Pn}_{\mathrm{sn}} / \mathrm{PI}_{\max }$ (fig 2; $r=+0.86$; $\mathrm{p}<0.0001)$, which indicates that as VC falls the absolute value of $\mathrm{Pn}_{\text {sn }}$ declines more than $\mathrm{PI}_{\max }$ - that is, $\mathrm{PI}_{\max }$ is greater than $\mathrm{Pn}_{\mathrm{sn}}$. Furthermore, the mean $\mathrm{Pn}_{\mathrm{sn}} / \mathrm{PI}_{\max }$ value was lower in patients with a VC $<40 \%$ of predicted than in patients with a VC greater $>40 \%$ of predicted $(0.86(0.35) v$ 1.04 (0.41); $\mathrm{p}<0.0001)$. When expressed in absolute values $\left(\mathrm{cm} \mathrm{H}_{2} \mathrm{O}\right), \mathrm{Pn}_{\mathrm{sn}}$ was less than $\mathrm{PI}_{\max }$ in 147 of the 241 patients.

\section{DISCUSSION}

As in previous studies of patients with neuromuscular disorders, we found a positive correlation between $\mathrm{Pn}_{\mathrm{sn}}$ and $\mathrm{PI}_{\text {max }}$, but with relatively poor agreement between these two tests. ${ }^{12}$ However, the present findings differ from previous studies ${ }^{16}$ in that the value of $\mathrm{PI}_{\max }$ was at least the same as or even greater than $\mathrm{Pn}_{\mathrm{sn}}$, particularly in those patients with

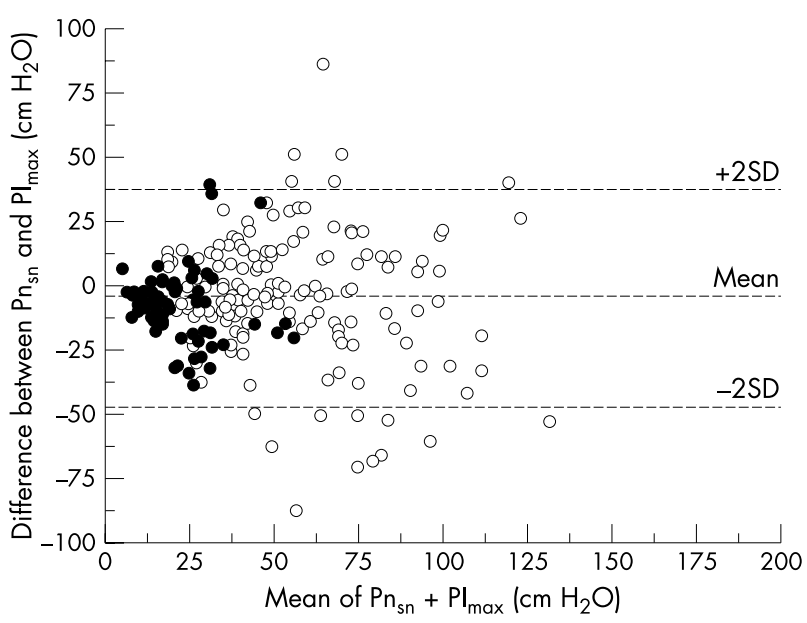

Figure 1 Bland-Altman plot: difference between sniff inspiratory nasal pressure $\left(\mathrm{Pn}_{\mathrm{sn}}\right)$ and maximum static inspiratory pressures $\left(\mathrm{Pl}_{\text {max }}\right)$ plotted against the mean of these two variables $(n=241)$. Filled symbols, patients with VC $<40 \%$ of predicted; empty symbols, patients with VC $>40 \%$ of predicted. VC, vital capacity.

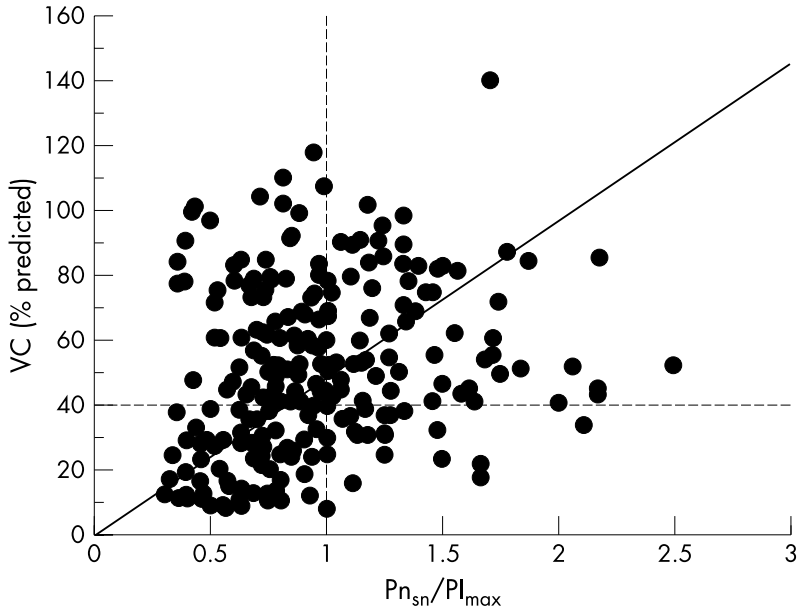

Figure 2 Relation between per cent predicted (\% predicted) vital capacity (VC) and sniff inspiratory nasal pressure, normalised for maximum static inspiratory pressure $\left(\mathrm{Pn}_{\mathrm{sn}} / \mathrm{PI}_{\text {max }}\right)(\mathrm{n}=241 ; \mathrm{r}=0.86$; $p<0.0001)$. Horizontal dashed line indicates VC (\% predicted) of $40 \%$ and the vertical line indicates unity between $\mathrm{Pn}_{\mathrm{sn}}$ and $\mathrm{PI}_{\max }\left(\mathrm{Pn}_{\mathrm{sn}} /\right.$ $\left.\mathrm{PI}_{\max }=1\right)$.

severe ventilatory restriction caused by neuromuscular disease. In fact, the present data are more consistent with, and extend, the observations of Iandelli et al, ${ }^{2}$ and highlight the limitation of $\mathrm{Pn}_{\mathrm{sn}}$ in this particular patient population.

Comparing our study with that of Stefanutti et al, ${ }^{1}$ there are two major differences. The first is that overall $\mathrm{Pn}_{\mathrm{sn}}$ is less than $\mathrm{PI}_{\text {max }}$; the second is that advanced lung restriction from severe neuromuscular disease is associated with a lower value for $\mathrm{Pn}_{\mathrm{sn}}$ than for $\mathrm{PI}_{\max }$. This disparity between the current study and Stefanutti's could be the result of technical differences, as both $\mathrm{Pn}_{\mathrm{sn}}$ and $\mathrm{PI}_{\max }$ manoeuvres in the earlier study were done without visual feedback. As sniffing is a more natural manoeuvre than $\mathrm{PI}_{\text {max }}{ }^{11}$ it is conceivable that without visual feedback $\mathrm{Pn}_{\mathrm{sn}}$ would be greater than $\mathrm{PI}_{\text {max }}$. In addition, in the Stefanutti study there were only three attempts at the unfamiliar $\mathrm{PI}_{\max }$ manoeuvre, but 10 sniff manoeuvres were done. In our clinical practice we get the patient to do at least three $\mathrm{PI}_{\max }$ manoeuvres or continue until two identical readings are obtained, ${ }^{7}$ and our greater $\mathrm{PI}_{\max }$ value may therefore be attributable to the learning effect. Furthermore, the current study differs from previous studies of patients with amyotrophic lateral sclerosis where facial muscle weakness and leaks around the mouthpiece were a major problem causing a reduction in $\mathrm{PI}_{\max }{ }^{12}{ }^{13}$

The results of our study are supported by the findings of earlier studies in patients with chronic stable inspiratory muscle weakness ${ }^{2}$ and in patients with acute respiratory failure, ${ }^{14}$ showing that $\mathrm{Pn}_{\mathrm{sn}}$ underestimates inspiratory muscle strength in patients with severe neuromuscular disease. Although we acknowledge that VC is an indicator of both respiratory muscle function and lung and chest wall compliance, it is more commonly used than $\mathrm{Pn}_{\mathrm{sn}}$ or $\mathrm{PI}_{\max }$ in clinical practice to monitor sequential changes in respiratory impairment as neuromuscular disease progresses. Furthermore, in patients with advanced restrictive ventilatory defects secondary to neuromuscular disease there are marked reductions in VC with relatively small changes in maximum pressures, owing to the curvilinear relation between VC and maximum inspiratory pressures ${ }^{15}$ - that is, VC is probably a more sensitive marker of disease progression in advanced disease than in mild disease. ${ }^{16}$

To explain the greater decline of $\mathrm{Pn}_{\mathrm{sn}}$ than of $\mathrm{PI}_{\max }$ in patients with severe neuromuscular disease, we must 
consider the mechanism of sniffing compared with the maximal static inspiratory manoeuvre. Sniff is generated during a ballistic manoeuvre where the inspiratory muscles shorten to a greater extent and at a higher speed than during a $\mathrm{PI}_{\max }$ manoeuvre, which is a more sustained isometric task. Thus as a result of both the force-velocity and force-length relations in striated muscle, $\mathrm{Pn}_{\mathrm{sn}}$ should be less than $\mathrm{PI}_{\max }-$ that is, pressure generation falls with a reduction in the operating length of the muscle and also with an increase in the velocity of muscle shortening. However, as sniffing is more natural than the maximum inspiratory static manoeuvre, it is believed that this accounts for the higher $\mathrm{Pn}_{\mathrm{sn}}$ than $\mathrm{PI}_{\max }$ value in normal subjects. ${ }^{6}$ Also, the value for $\mathrm{Pn}_{\mathrm{sn}}$ is measured from the peak pressure, whereas $\mathrm{PI}_{\max }$ is the average pressure sustained over one second, which includes an early peak pressure before falling off to a lower sustained pressure. Thus whichever of these two effects is greatest will influence the value of $\mathrm{Pn}_{\mathrm{sn}}$ more than $\mathrm{PI}_{\max }$. Nevertheless, patients with severe neuromuscular disorders may not be able to perform a rapid sniff manoeuvre owing to significant muscle atrophy. Furthermore, because of the differences in the type of effort and the pattern of muscle activation in the two manoeuvres, the $\mathrm{Pn}_{\text {sn }}$ value and $\mathrm{PI}_{\max }$ value probably reflect different aspects of inspiratory muscle function. Thus a more sustained manoeuvre may achieve a greater pattern of inspiratory muscle activation in severely affected patients.

\section{CONCLUSIONS}

In patients with moderate to severe neuromuscular disease, overall $\mathrm{PI}_{\max }$ yielded similar values to $\mathrm{Pn}_{\mathrm{sn}}$. Although there was a close correlation between $\mathrm{Pn}_{\mathrm{sn}}$ and $\mathrm{PI}_{\max }$, there was a relatively poor agreement between the two variables, and the value for $\mathrm{PI}_{\max }$ was higher than $\mathrm{Pn}_{\mathrm{sn}}$, particularly in patients with a severe restrictive ventilatory defect. $\mathrm{Pn}_{\mathrm{sn}}$ may overestimate the level of inspiratory muscle weakness, which challenges the view that this is the most appropriate test in this particular group of patients. We therefore suggest that $\mathrm{PI}_{\max }$ and $\mathrm{Pn}_{\mathrm{sn}}$ are not interchangeable but are complementary tests and should be used in combination with VC for a complete sequential assessment of inspiratory muscle strength in patients with neuromuscular disease.

\section{ACKNOWLEDGEMENTS}

$\mathrm{NH}$ is funded by a grant from the Association Française Contre Les Myopathies, the Scadding-Morriston Davies respiratory medicine award, and a European Respiratory Society long term fellowship.

\section{Authors' affiliations}

N Hart, M I Polkey, Respiratory Muscle Laboratory, Royal Brompton

Hospital, Fulham Road, London, UK

T Sharshar, Service de Réanimation Médicale, Raymond Poincaré

Hôpital, Garches, France

L Falaize, F Lofaso, Service de Physiologie-Explorations Fonctionnelles, Raymond Poincaré Hôpital, Garches, France

B Fauroux, Paediatric Pulmonary Department, Armand Trousseau Hospital-AP-HP, Paris, France

J C Raphaël, Service de Réanimation Medicale, Raymond Poincaré Hôpital, Garches, France

Competing interests: none declared

\section{REFERENCES}

1 Stefanutti D, Benoist M-R, Scheinmann $P$, et al. Usefulness of sniff nasal pressure in patients with neuromuscular or skeletal disorders. Am J Respir Crit Care Med 2000; 162:1507-11.

2 landelli I, Gorini M, Misuri G, et al. Assessing inspiratory muscle strength in patients with neurologic and neuromuscular diseases (comparative evaluation of two non invasive techniques). Chest 2001;119:1108-13.

3 Clinical indications for noninvasive positive pressure ventilation in chronic respiratory failure due to restrictive lung disease, COPD, and nocturnal hypoventilation-a consensus conference report Chest 1999;116:521-34.

4 Heritier F, Rahm F, Pasche P, et al. Sniff nasal pressure. A noninvasive assessment of inspiratory muscle strength. Am J Respir Crit Care Med 1994; 150:1678-83.

5 Black LF, Hyatt RE. Maximal respiratory pressures: normal values and relationships to age and sex. Am Rev Respir Dis 1969;99:696-702.

6 Uldry C, Fitting J-W. Maximal values of sniff nasal inspiratory pressure in healthy subjects. Thorax 1995;50:371-5.

7 Wilson SH, Cooke NT, Edwards RHT, et al. Predicted normal values for maximal respiratory pressures in Caucasian adults and children. Thorax 1984;39:535-8.

8 Laporta D, Grassino A. Assessment of transdiaphragmatic pressure in humans. J Appl Physiol 1985;58:1469-76.

9 Quanjer PH. Stanadardized lung function testing. Eur Resp J 1993;6/suppl 16):5-30s.

10 Bland JM, Altman DG. Statistical methods for assessing between two methods of clinical measurement. Lancet 1986;i:307-10.

11 Polkey MI, Green M, Moxham J. Measurement of respiratory muscle strength. Thorax 1995;50:1131-5.

12 Lyall RA, Donaldson N, Polkey Ml, et al. Respiratory muscle strength and ventilatory failure in amyotrophic lateral sclerosis. Brain 2001;124:2000-13.

13 Fitting J-W, Paillex R, Hirt L, et al. Sniff nasal pressure: a sensitive respiratory test to assess progression of amyotrophic lateral sclerosis. Ann Neurol 1999:46:887-93.

14 Heritier F, Perret C, Fitting J-W. Maximal sniff mouth pressure compared with maximal inspiratory pressure in acute respiratory failure. Chest 1991;100:175-8.

15 DeTroyer A, Borenstein S, Cordier R. Analysis of volume restriction in patients with respiratory muscle weakness. Thorax 1980;35:603-10.

16 ATS/ERS. American Thoracic Society/European Respiratory Society. ATS/ ERS statement on respiratory muscle testing. Am J Respir Crit Care 2002;166:518-624. 